\title{
Passion-driven entrepreneurship in small and medium-sized towns: empirical evidence from Italy
}

\author{
Alessandro Pagano, Francesco Petrucci and Roberta Bocconcelli \\ Department of Economics, Society and Politics, University of Urbino Carlo Bo, Urbino, Italy
}

\begin{abstract}
Purpose - This paper aims to examine the emergence of passion-driven entrepreneurship within the context of small and medium-sized towns (SMSTs). SMSTs are seen as peripheral areas lacking the resources to support autonomous economic development and renewal. The paper explores the relationship between entrepreneurship and the context of SMSTs through the concepts of entrepreneurial passion (EP) and domain passion (DP). Industrial marketing and purchasing approach is adopted as a theoretical foundation to conduct the analysis through the actors-activities-resource framework.

Design/methodology/approach - This paper adopts a multiple case-study methodology. Two passion-driven entrepreneurial ventures (PDEVs) have been traced from the conception of the initial idea until the new ventures establishment.

Findings - EP and DP emerge as key resources in transforming the initial idea into a real entrepreneurial venture in resource-scarce settings as SMSTs. Shared passion fosters the involvement of local actors and the propensity to overcome relevant hurdles in the entrepreneurial process.

Originality/value - This paper contributes to the literature on entrepreneurship through the analysis of the role of PDEVs in SMSTs' contexts. It highlights the role of "passion for place" as a new dimension of passion in entrepreneurial studies. From a managerial perspective, it emphasizes the role of passion as a key resource for networking and marketing. From a policy perspective, it calls for monitoring and support for training, funding and networking.
\end{abstract}

Keywords IMP, Business network, Entrepreneurial passion, Domain passion, Passion-driven entrepreneurship, Small and medium-sized towns

Paper type Research paper

\section{Introduction}

In the entrepreneurship literature, there has been growing recognition of the importance of studying entrepreneurship as a contextualized phenomenon (Welter and Gartner, 2016). A new venture can be better understood if captured from within the multiple contexts - spatial, social, economic and institutional - in which it takes place; the context not only provides the new venture with opportunities, yet sets the boundaries for its development path (Welter, 2011; Welter and Gartner, 2016; Welter et al., 2019).

According to this view, many researchers have started exploring the relationship between entrepreneurship and peripheral contexts, which are traditionally seen as poor environments (McKeever et al., 2015). It is longtime that policymakers and scholars see entrepreneurship as a key driver for the economic growth and renewal of peripheral areas (Johannisson and Nilsson, 1989). It is thus not surprising that the context of small and medium-sized towns (SMSTs) is gaining growing attention in research (Servillo et al., 2017). This attention is because of several reasons: first, SMSTs are distributed throughout all the European territory, as around $56 \%$ of the European urban population live in SMSTs; second, the specific "small and medium" urban types have great

The current issue and full text archive of this journal is available on Emerald Insight at: https://www.emerald.com/insight/0885-8624.htm

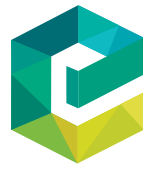

Journal of Business \& Industrial Marketing 36/13 (2021) 210-219

Emerald Publishing Limited [ISSN 0885-8624] [DOI 10.1108/JBIM-05-2019-0259] historical, cultural and social relevance in Europe; third, SMSTs still play an important economic role for the development of peripheral regions and rural areas. Nevertheless, these places have been only marginally studied by urban and economic geography research, primarily interested in analyzing policy actions and economic development in more dominant areas such as core regions and large urban agglomerates (Bell and Jayne, 2009).

This paper aims to contribute to research on entrepreneurship in peripheral contexts by exploring the role of passion in the emergence of entrepreneurial ventures in SMSTs contexts. Undoubtedly, the dimension of passion has gained interest as a key driver of entrepreneurial action (Newman et al., 2019). Two key conceptualizations have emerged: on the one hand, there is an orientation to explore the nature of "entrepreneurial passion" (EP), mainly related to the entrepreneurial effort itself (Cardon et al., 2009); on the other hand, more recent contributions emphasize the role of "domain passion" (DP), which is associated with people's personal interests and hobbies and is related to

\footnotetext{
(C) Alessandro Pagano, Francesco Petrucci and Roberta Bocconcelli. Published by Emerald Publishing Limited. This article is published under the Creative Commons Attribution (CC BY 4.0) licence. Anyone may reproduce, distribute, translate and create derivative works of this article (for both commercial and non-commercial purposes), subject to full attribution to the original publication and authors. The full terms of this licence may be seen at http://creativecommons.org/licences/by/4.0/legalcode
}

Received 31 May 2019

Revised 9 December 2019

15 March 2020

26 June 2020

Accepted 21 July 2020 
activities developed in free-time (Milanesi, 2018). This focus on passion in shaping entrepreneurial processes has led to the emergence of a stream of research on "passion-driven entrepreneurship," as shown in recent contributions (Cannatelli et al., 2019; Guercini and Ceccarelli, 2020). This research effort is also driven by the recognition of the possible impact of passiondriven entrepreneurship on local development paths (Guercini and Cova, 2018).

The present study aims to expand knowledge about entrepreneurship in SMSTs contexts through the analysis of the role of passion in shaping new ventures in such peripheral and resource-scarce settings. To the best of our knowledge, in the existing literature there is still a lack of attention to the potential role of passion as driver of entrepreneurship in such contexts. To achieve the research objective, this paper explores how passion-driven entrepreneurial ventures (PDEVs) emerge and develop within SMSTs contexts, highlighting relevant factors facilitating or hindering such processes. Notably, we intend to address the following research question:

\section{RQ1. How do PDEVs emerge within a SMST context?}

The industrial marketing and purchasing (IMP) approach is used as the theoretical foundation to explore the embedding context of the new venture in terms of business relationships and networks (Håkansson et al., 2009), with a particular focus on the actors, resource and activities dimensions (Håkansson and Snehota, 1995). The IMP approach emphasizes how different networks shape a new venture startup and development (Baraldi et al., 2018). This perspective is deemed useful to cast new light on the role of passion in entrepreneurial ventures in SMSTs, as these contexts are characterized by local communities sharing values and interests and by businesses deeply embedded in local networks (McKeever et al., 2015). A multiple case research methodology is adopted to capture the development process of PDEVs and the role of their SMSTs' contexts (Easton, 2010). Two different cases are introduced and discussed to compare data from distinct contexts. The first case describes a small entrepreneurial team of artists leading the organization of an annual art festival and trade fair in the city of Macerata in central Italy: the RATATÀ Festival. The second case is about two friends committed to organizing ARIA a fair/event in the building/furnishing sector in the city of Fano in central Italy - and to transform their project in a business start-up.

The paper is structured as follows. Section 2 draws the theoretical background of the paper. First, the previous literature on entrepreneurship, SMSTs and passion is examined, and then the IMP approach and IMP-related entrepreneurship studies are introduced and discussed. Research methodology is presented in Section 3. Section 4 concerns the empirical analyses of the two cases. Section 5 addresses the main findings of the analysis. Section 6 outlines the contribution of the study, its limitations and the main managerial and policy implications.

\section{Theoretical background}

\subsection{Entrepreneurship, small and medium-sized towns'} contexts and the role of passion

The importance of studying the link between entrepreneurship and its contexts has long been acknowledged in the literature
(Welter et al., 2019). There has been a growing recognition that entrepreneurial behavior can be better understood within its cultural, institutional, spatial and social contexts, which provide entrepreneurs with opportunities and set boundaries for their actions (Welter, 2011; Welter and Gartner, 2016). Accordingly, many scholars have moved from traditional research following a decontextualized "standard model" of entrepreneurship - conceived mainly as a profit-focused, highgrowth and technology-driven phenomenon - toward a more varied and comprehensive approach to entrepreneurship (Welter, 2011; Welter et al., 2017).

The contextualized approach to entrepreneurship has shown that a new venture systematically "embeds into" the existing social structure through the entrepreneur's network of interpersonal relations, bonds and local ties (Hite, 2003). Embeddedness is conceived in a strict "spatial" sense, as a localized description of the socio-economic context in which a business operates. This has allowed recognizing the role of local communities in entrepreneurship (Sharafizad and Brown, 2020; Trettin and Welter, 2011; Johannisson and Nilsson, 1989), which have been defined as localized social network-like structures that facilitate access to opportunities and local resources for entrepreneurship (McKeever et al., 2015). Within the community context, the joint development of resources and activities is often characterized by non-monetary factors such as trust and reciprocity that allow the alignment of goals among actors (Hite, 2003). SMSTs are generally considered as community-based contexts showing stronger local embeddedness of economic activities than larger urban conglomerates. However, SMSTs contexts have been scarcely investigated by prior research focused mainly on large urban areas and core regions (Lysgård, 2016; Bell and Jayne, 2009). Only a few studies have explored in detail he unique characteristics of SMSTs as a business context (Mayer and Motoyama, 2017).

The community dimension in entrepreneurship has been recently emphasized in the stream of studies focusing on "unconventional entrepreneurship" (Guercini and Cova, 2018). This research has highlighted the role of personal passion in the development of new ventures. Passion has become a key concept in entrepreneurship research, as shown in the recent literature review by Newman et al. (2019). Within this stream of studies, two key concepts have emerged: EP and DP. EP is conceptualized as a "consciously accessible, intense positive feeling experienced by engagement in entrepreneurial activities associated with roles that are meaningful and salient to the self-identity of the entrepreneur" (Cardon et al., 2009, p. 517). Scholars have started investigating the specific dimensions of EP, such as passion for growth, passion for competition, passion for inventing, passion for social mission and passion for people (Cardon et al., 2017). Some contributions emphasize the possible "emotional contagion" toward employees and other stakeholders, thus leading to a stronger commitment in new venture development (Cardon, 2008).

Recently some scholars have placed emphasis on passion related to hobbies, personal interests and leisure activities. They introduce the concept of DP, defined as "target-specific passion, that implies the existence of a specific domain that is the origin of one's affective experiences but also the target toward which one is motivated to fulfill a persistent effort" (Milanesi, 2018, p. 425). 
This push toward entrepreneurial action could also be oriented toward non-profit activities, thus inducing individuals to pursue the benefit of the local community. Other scholars conceive the specific domain also in relation to the specific content of business activities within firms, as shown by the "passion for product" typology (Cannatelli et al., 2019).

To explore more in-depth the role of passion in entrepreneurship in SMSTs contexts, characterized by a mix of community-based and business-oriented networks, we adopt the IMP perspective. This conceptual approach is considered a useful tool to explore contextualized entrepreneurial processes in the light of its emphasis on relationships and networks.

\subsection{Entrepreneurship in the industrial marketing and purchasing perspective}

The IMP approach substantially differs from a traditional view of the business in the sense that it considers interaction as the substantive nature of business reality. Interaction occurs at three layers as well as between the three layers: actors, resources and activities (ARA) (Håkansson and Snehota, 1995). The interaction process - shaping activities and resources - within dyadic relationships is further connected to a wider network of relationships (i.e. business network) where the two actors are involved (Håkansson et al., 2009).

IMP research studies have been increasingly concerned with the theme of new business formation and development. These studies highlight that while the entrepreneurship literature has focused on the social relationships of the entrepreneur and his/ her role in the networking process behind starting up a business, less attention has been paid to the substantial and complex business relationships in these entrepreneurial processes (Aaboen et al., 2017). This is in line with recent contributions in entrepreneurship calling for a deeper understanding of the actual dynamics of the entrepreneurial process that relies on a larger network of relationships and resources than the "entrepreneur-centric" ones (Welter et al., 2017).

The IMP view emphasizes the importance of the initial business relationships and actors' interactions in the starting phase of the venture, and on the role of resources' interaction in progressively shaping its development (Snehota, 2011; Ciabuschi et al., 2012; Baraldi et al., 2018). From the business relationships/actors' interaction point of view, it has been emphasized how the primary challenge in the starting phase is to relate the emerging venture to the already existing business network by a continuous action of combining and adapting in an uncertain and evolving context (Havenvid and La Rocca, 2017). By taking the resource side, IMP-based research on new business ventures emphasizes "the formation of the new business [...] as a collective rather than an individual act" (Ciabuschi et al., 2012, p. 228).

This "collective" perspective on business formation has consequences for the way the process of new business development can be analyzed to catch its main critical aspects (Havenvid and La Rocca, 2017). First, it can be observed that pre-existing business relationships have to be matched with emerging new ones strictly connected to the formation of the new business. Second, resources constantly change with respect to different uses and activities undertaken by the different actors involved (Håkansson and Snehota, 1995).
We argue that this perspective is particularly suited to shed light on the process of development of PDEVs within a SMST context. In fact, on the one hand, it can be easily acknowledged that passion is strongly rooted at the individual/entrepreneurial level; on the other hand, PDEVs cannot be analyzed in a detached way from the wider context - in terms of social and business relationships - in which the initiative takes place.

\section{Methodology}

To address the research question, this paper adopts a multiple case-study methodology (Yin, 2003). The development process of two ventures arising in the context of two small cities has been examined from the conception of the initial idea until the establishment. The qualitative case-study approach has been chosen first in the light of the explorative and descriptive nature of the research expressed in the "how?" form of the research question (Halinen and Törnroos, 2005) - and second because the case study methodology is particularly suitable to capture the relationship between a focal phenomenon and its embedding context, which is the focus of this research. To enable a network perspective on our analysis, the two cases have been developed relying on the IMP ARA model as conceptual and methodological foundation (Håkansson and Snehota, 1995). The ARA model has allowed us to explicitly focus on the establishment of resource combinations, activity links and actor bonds in the creation process of the new ventures.

The choice of developing a multiple case study is justified by the need to find meaningful recurrences and differences in our contextual analysis. Purposeful sampling (Patton, 1990) was used to select the cases, on the basis of a set of common contextual features and their relevance in the development of the entrepreneurial ventures. In particular, the study explores how two new ventures, namely, the RATATÀ Festival - a three-day art event and trade fair - and ARIA - a three-day fair/ event in the construction sector - emerge and develop in the context of the local communities of Macerata and Fano, respectively. Both towns can be classified as SMSTs - with a population within 5,000 and 100,000 - (CEC, 2011) and are located in the Marche Region of Italy. They show similar social, cultural, institutional and economic background characteristics and structures. RATATÀ can be considered as a "not-forprofit" venture, while ARIA relies more on a business-oriented dimension.

Data on the RATATÀ case were collected between January and May 2017, focusing on the first four editions. While the starting-up phase and the first three editions of the festival have been traced back through a retrospective reconstruction of the main organizational events and processes, the fourth one has been followed in "real-time," through interviews and direct observations. The primary source of data is represented by 15 semi-structured interviews lasting 30-75 min each, conducted with the 4 members of the entrepreneurial team. Data on ARIA have been collected mainly between February and March 2018 through three open-ended interviews conducted with the two founders. Another relevant source of data is represented by the Bachelor of Arts dissertation of one of the founders, where detailed accounts of the venture are presented and explained according to the founder's perspective. 
In both cases, follow-up interviews, phone calls and secondary data such as websites, newspapers interviews, internal reports, social-media activities, promotional and communication campaigns and crowdfunding campaigns, have been used to complete data collection and support the ex-post reconstruction of early stages. Each interview was recorded and transcribed.

Data analysis followed a systematic combining procedure, adopting an abductive approach (Dubois and Gadde, 2002) following the explorative nature of the case research based on a logic of investigation aimed at matching theory and empirical observations recursively. Systematic combining is suitable for studying a new or under-researched phenomenon while also paying attention to existing theories around the topic (La Rocca et al., 2017). Finally, we coded the analysis into common themes concerning the role of the small-town context in entrepreneurship to link empirical observations to theoretical knowledge. The cases have been presented as divided into temporal phases following the various editions of the events (Quintens and Matthyssens, 2010).

\section{Empirical analysis}

\subsection{RATATÀ case}

This section analyzes the conception, launch and development of RATATÀ, an international art fair and festival dedicated to independent publishing, illustration and comics that takes place every year in the town of Macerata, a medium-sized town with a population of 41,865 (in 2017), located in Central Italy. Macerata has recently experienced a decline in its economy based traditionally on the footwear industry. The Festival was first launched in April 2014 and its fourth edition was held in April 2017.

\subsubsection{From the idea to the first edition of RATATÀ}

The idea of developing an art festival in Macerata came up in 2014 when Lisa, a professional Graphic Designer living in the town, decides to respond to a public call of the regional government aimed at promoting projects in cultural sectors. During one of the meetings of the cultural association Teatro Rebis, Lisa explicitly stated: "I want to organize a Festival!" The idea was highly ambitious given the fact that despite the presence of influential cultural institutions such as the "Accademia di Belle Arti di Macerata" and the "Università degli studi di Macerata," the town was characterized by a significant lack of dedicated contemporary art events. However, the town is still inhabited by a large community of amateur artists and creatives, students as well as cultural associations and other organizations actively engaged in cultural production. When the opportunity to be financed by the regional government turns out, Lisa conceives the idea of realizing an independent art festival in Macerata with Nicola and Lorenzo, two friends of her and amateur artists:

We attended many art festivals together around Italy. However, why we develop a festival here in Macerata - we asked ourselves! Macerata could be a potential breeding ground for these activities given the presence of the "Accademia di Belle Arti" and "Ars in Fabula", and Lisa has immediately understood this opportunity. (Lorenzo)

Nicola and Lorenzo are both from Macerata and spend much time within the art community. Nicola is a professional Graphic
Designer, while Lorenzo runs a small home-based woodworking business.

The initiative starts when the regional government accepts to finance the project of Lisa, Nicola, Lorenzo and Teatro Rebis:

We felt inspired by our interests, passions, and experiences, all converging toward graphic design, illustration, and comics. We were aware of the many resources of the town: the Accademia with its passionate students, or the large circle of amateur artists - such as the former students of the Accademia - living in the town. We were convinced to be able to involve all these people. (Nicola)

Lisa, Nicola and Lorenzo work hard to mobilize the necessary resources to develop the festival and use their contacts with the local community. A key resource is represented by the volunteer members. The founders soon involve Enrico, a friend and professional editor, as a partner for the focal team. Enrico is the owner of "Stranedizioni," an independent small publishing house specialized in realizing hand-crafted artist-books. Because of his business, Enrico can connect to an external network of artists, associations, micro-businesses and freelancers in the art publishing sector. For the first year, the RATATÀ festival is entirely located at "Centro Sociale Sisma" of Macerata, an important meeting place for the community.

Many other members of the community - such as cultural associations, or local small businesses such as cafés, restaurants and pubs - self-mobilize to join the festival organization by offering facilities for exhibitions as well as organizational support for connected activities, such as workshops, concerts or evening parties.

Finally, on April 11, 2014, the first edition of the RATATÀ Festival is launched. The festival consists of a rich 3-day program of events, including the trade fair with almost 40 exhibitors, 5 exhibitions, 60 hosted artists and 10 connected events among workshops, concerts and entertainment events; all this with an audience of 3,000 visitors.

\subsubsection{RATATÀ second and third edition}

The first edition receives an enthusiastic and also unexpected response from the public, the exhibitors and the entire local community. The positive feedback pushes the team to give a chance to the second edition of the festival. However, Lisa, Nicola, Enrico and Lorenzo cannot count on the financial support previously obtained through the regional government. However, they are strongly motivated to develop further the festival.

The willingness to move forward is supported by the desire to share and undertake the project together:

Art and graphic illustration is a common ground for all of us, but without the passion for "doing something altogether" all this would have never been done. (Lorenzo)

In particular, the team feels the need to involve the town of Macerata:

We wanted to involve people in our city. An art festival makes sense if its mission includes the cultural growth of the entire territory. Unfortunately, this is not always the case, and that is why we worked hard to make RATATÀ something different. If you get your place to connect with the cultural circuit you represent, then you create a stable structure for your activities, as well as more stable relationships in order for the festival to develop further. (Nicola)

The team starts involving the municipality by asking for a public contribution and collaboration. In the meanwhile, a crowdfunding campaign is launched through the platform Ulule. The municipality grants only limited economic support; 
nevertheless it provides an opportunity for the festival to use the most prestigious buildings in Macerata. To better manage relations with the many surrounding actors, the founding team chooses to formalize the organizational form of the festival and in January 2015 a novel cultural association named RATATÀ is set up. The call for a second edition is welcomed with great enthusiasm by the community and new groups of volunteers join the organization. The second edition of the RATATÀ festival is finally launched in April 2015. This edition counts on a wide and varied program of events building on a larger group of 60 exhibitors, 15 exhibitions, 80 international hosted artists and almost 25 connected events; all this with an audience of 4,000 visitors in 3 days.

RATATÀ results from the cooperation of artists, illustrators, cartoonists, publishers, and social spaces. RATATÀ virally invades the city to advance a new way to live and perceive the urban space. These events outline culture as a driver of social empowerment and growth. Thinking about the city as a place of production and not as a series of inaccessible spaces. (CSA Sisma Ulule.com)

The success of the second edition pushes the organizers to plan a third one. Lisa, Nicola, Lorenzo and Enrico are more committed to relocating the festival in the town center, transforming RATATÀ in the festival of the town and of the community.

In this way, the festival brings the town to life through animating its bars, cafes, parks, squares, sidewalks and heritage buildings. Ulule and the municipality prove to be, for the second year, two reliable sources of financing.

The third edition is the biggest, and the numbers confirm this great success: more than 100 exhibitors from all over Europe, 30 exhibitions, more than 100 international single artists and collectives, almost 40 connected events and an audience of more than 5,000 visitors in 4 days. The success of the third edition of the RATATÀ Festival inevitably has transformed this event into a potential business opportunity in the hands of the project team. RATATÀ has become a recognizable brand for several artists and collaborators producing their artworks under the collective name of RATATÀ.

\subsubsection{RATATÀ fourth edition}

The team has to face the difficulty to organize the fourth edition of the festival while dealing with consequences of the tragic earthquakes that occurred in central Italy and Macerata in 2016. However the team is committed to help the city keeping the promise to continue this initiative.

The festival can rely on a well-defined organizational structure. Relationships with external institutions and business actors also consolidate thanks to the increasing commitment of the local community toward the event. On the financing side, the mix between public patronage and crowdfunding on Ulule has remained important. The municipality has renewed its economic contribution and organizational commitment, also adding extra support mainly in the form of equipment, promotion services and facilities.

The increasing number of activities is somehow hindering the ability and the opportunity of the team to turn the RATATÀ brand into a viable new business venture. The format is successful and self-sufficient, and for the team, there are no reasons for an effective new business venture to be developed, also because in their view, changing the non-profit nature of the festival is perceived as a risky operation:
We experienced many contrasts among us before and during the organization of the event, but none of us has other purposes. We do it only for passion and to make it grow and make it known everywhere. Under this perspective, we have done a lot. (Lorenzo)

\subsection{ARIA case}

This section analyzes the conception, launch and development of ARIA, an event/fair dedicated to professionals, firms, organizations and associations in the construction/furnishing industry. The event is held in Fano, a small town, with a population of 60,852 (in 2017), situated in the Marche Region of Central Italy. ARIA was first launched in September 2016 and its second edition was held in September 2017.

\subsubsection{Birth and launch of the first edition}

In the fall of 2014, Fabio and Cora start discussing working together on sustainable housing. They both live in Fano, have been knowing each other for many years, have construction/ housing-related competences, share a keen interest in sustainability and innovation and show an "entrepreneurial" attitude influenced by their family culture. Fabio is a secondgeneration entrepreneur working in his small family business (materials for interiors and furniture). While working in the family firm, Fabio is interested in exploring different professional contexts, also to prove his entrepreneurial abilities. Cora is a Civil Engineer working as a professional in the building sector and recently opened a "co-working" activity leaving the professional engineering consulting firm owned by her father. Cora is interested in developing her project/venture and in showing her technical ability.

When they meet and involve a local friend - active in the organization of events in cooperation with the municipality they start thinking about a "construction trade fair" in the light of their complementary skills. They are mainly interested in diffusing their passionate concern about "building/furniture culture" through the combination in one single event of three main components: historical downtown, business world and the cultural dimension of building and furniture industries. Cora is very keen on developing the project:

The idea is linked to many reasons: the hard life in the construction industry for a woman, the desire of showing to my family the ability to make my things, the personal satisfaction in seeing your creature growing up [...] An event like this is close to my personal goals.

The three friends start discussing the project and choose the name: ARIA - which is the acronym for furniture, recycling, innovation and architecture, that in Italian means "air" and recalls a meaning of sustainability and green power. In 2016, a new start-up company is established to formally manage relationships and contracts with exhibitors, which Fabio and Cora start to contact and involve thanks to their personal and business networks, and with professionals and firms providing support services for the event. However, in this phase, unexpectedly, their new local partner leaves the team. Notwithstanding this initial problem, Fabio and Cora are committed to carrying on with their project scheduled for September 2016. ARIA is planned as a three-day event and is supposed to represent the first public local event explicitly combining the cultural/entertainment dimension with the business/technical dimension. Exhibitors welcome the choice of locating the event in the historical downtown, and this encourages the organizing team to move forward: 
The historic downtown is the place where the event has been planned since the beginning. Knowing this was the right choice, we obtained the energy and motivation to face such a long and complex project. (Fabio)

Once date and location are fixed, Fabio contacts the two closer universities and Cora is successful in involving the leading local professional associations, where she has been active in the past. Then they start contacting possible exhibitors, which are positively impacted by the institutional support to ARIA and by the choice of the historical location in the downtown Fano, providing stronger local identity to the event. The propensity of businesses to accept the proposal by the ARIA team is also motivated by their perception of the attitude of the organizers, as Fabio states:

The exhibitors were impressed by the enthusiasm that we have been able to transmit [...] they trusted us because we transmitted much passion in what we were doing [...] We were in empathy with the project [...] It was the fact that we strongly believed in the project that attracted the exhibitors.

Fabio and Cora are also aware of the need to find additional support, given their half-time involvement in their professional jobs. Some friends have been involved on a volunteer basis for their organizational and technical competences. Professional providers - video making and logistics - are involved with contractually based compensation. Designing the event layout has been a very complex activity, especially if considering the "street" dimension of ARIA. In addition organizers have to guarantee the financial sustainability of the project both in the short and the long term. Anticipated payment by exhibitors based on reciprocal trust - allows for activating collaborations with technical services providers needed for the organization of ARIA.

The first edition is very successful: a total of 46 exhibitors, 14 seminars/workshops and about 8 collateral entertaining events. Exhibitors - surveyed by the organizers after the event - express their appreciation about the beauty of the location, the "openair" organization of the event, the high attendance and interest of visitors and the value of new business opportunities related to the event.

Exhibitors liked the idea that companies "move towards visitors and customers" showing their offering and competences in the historical town center. There has been intense interaction among exhibitors, leading in some cases to new joint projects. The impact of ARIA has been relevant for small family firms, which in many cases experienced their first real "exhibition" experience in an innovative and familiar context.

\subsubsection{Second edition of ARIA}

The positive evaluation by exhibitors represents a key factor in pushing the ARIA team to start planning the new edition in 2017. Notwithstanding this first successful experience, Fabio and Cora are aware about the problems faced in the first edition: the complexity of organizing a new event and in a parallel, setting up a start-up; the high managerial burden faced exclusively by the co-organizers; and the limited financial support. Fabio and Cora start working on the new edition with the stated goal to make ARIA one of the most important events in Fano and the regional context.

The co-organizers are aware that the new edition requires a more careful planning and more effort in fundraising, to involve private sponsors and to obtain funding from the local municipality and other public organizations. The network of partnering cultural associations and organizations is widened to new local actors to improve the entertainment/cultural dimension of the event.

The upgrading of the ARIA project is possible only with additional organizational resources. Fabio and Cora involve young university interns for organizational tasks and strengthen their business network of partner firms and professionals. In the meanwhile, Fabio and Cora keep on involving their group of friends in the discussion of new ideas concerning the ARIA event.

Also the second edition proves successful. The total number of exhibitors increases to from 46 to 56; the event is organized in an historical open space and also in surrounding historical buildings. Technical seminars/workshops increase from 14 to 25 and cultural collateral events increase from 8 to 12 . Exhibitors put a stronger commitment in the organization of their presence and are more aware of the benefits of investments in exhibition activities:

Relationships with exhibitors have changed [...] they are more passionate about the event [...] in the first edition they have been surprised, while in the second edition they wanted to show what they are capable of doing [...] always within a familiar environment. (Cora)

Therefore after the second edition, ARIA gains the full recognition of the local municipality and sets new standards for other town events, whose organizers start imitating ARIA in terms of project planning and organization. The organizers Fabio and Cora and ARIA have positive returns and feedback, increasing their professional reputation related to their primary professional employment. ARIA and the organizers are sometimes contacted for providing consulting and advice on both technical and managerial projects, related to the organization of events.

\section{Discussion of results}

RATATÀ and ARIA cases offer interesting insights about the development of passion-driven entrepreneurship in SMSTs contexts. In both cases, the initial idea has been transformed into an entrepreneurial venture which has evolved through increasing embeddedness within their respective SMSTs contexts, generating a positive impact on the local communities and businesses. In both cases, entrepreneurial teams have been able in facing and overcoming complex problems - in terms of limited financial resources, mixed support by local institutions and lack of experience in the organization of events.

This section aims to discuss the main findings of the empirical analysis previously outlined using the ARA model as the main conceptual framework to highlight the key components of the trajectories of the two PDEVs.

In both cases, individual and organizational actors play relevant roles in the various phases of their evolution (McGrath et al., 2019). The emergence of the initial idea is the result of the interaction among a group of individual actors - therefore, it is not the outcome of a single individual - shaped by friendship and characterized mainly by non-profit motivations. Afterwards, the initial attempts show the involvement of other individual actors - always based on friendship - acting as collaborators on a volunteer basis in RATATÀ and as professional support in ARIA. In this first phase also, several local organizations within the SMSTs contexts - associations, 
local institutions and firms - come into play in the context of the new venture development. Most of them agree with the "idea" and show an "explorative" approach accepting to provide initial support sharing the "risk" of the initiative. Therefore in both cases, the venture since the beginning, shows a spontaneous collective nature (Ciabuschi et al., 2012) around a project, where the leading entrepreneurial teams involve through trust and "contagion" - the existing local social and business networks. In this phase, local institutions interact passively with the entrepreneurial group. In the further development of the project - corresponding to the second edition of RATATÀ and the first edition of ARIA - the leading group of individual actors recognizes the need to evolve into an organizational entity - a cultural association in the case of RATATÀ and a business start-up in the case of ARIA - to overcome initial difficulties facilitating - substantially and formally - the development of relationships with business and institutional actors. Therefore in this development phase, the social - interpersonal - and business networks co-evolve (Havenvid and La Rocca, 2017) and the latter start to include actors external to the SMST context - as the crowdfunding platform Ulule in the RATATÀ case and the surrounding universities in the case of ARIA. In the latter phase examined in the empirical analysis - corresponding to the third/fourth editions of RATATÀ and the second edition of ARIA - there is a consolidation of the entrepreneurial team leading the ventures, an enlargement of the close network of external supporting actors and a widening of the number of participants to the projects. Concerning the activities undertaken in the development of the two ventures, it could be argued that their features and evolution depend on their event-related nature. In the initial phase, activities are implemented in a mainly informal and unstructured manner, strongly influenced by the complexity and the "work-in-progress" nature of both projects. In the following phases, activities have become more formalized and structured and a more clear division of tasks has been implemented within the organizing team. This evolution has been facilitated by the setting up of organizational entities.

With regard to resources, the analysis of RATATÀ and ARIA cases provides many interesting insights. The first striking consideration is that both events represent successful ventures with very limited resources. Therefore, the analysis of the nature of resources in play in the evolution of the two ventures is key for understanding what has happened in the two cases. In terms of financial resources, both leading entrepreneurial teams, since the beginning, face a shortage very challenging to overcome. On the one hand, they both try to gain access to public funding and - in the RATATÀ case - private financing through crowdfunding platforms; on the other hand, they pursue collective contributions in terms of non-financial exchanges - the RATATÀ case (Hite, 2003) - or more traditional payment for services - as in ARIA case. One relevant aspect is that in the initial phase, these contributions have been made within a sort of co-sharing pattern with limited guarantees about the outcomes of projects. This consideration leads to examining the role of other key resources - emerging in the process - which made these ventures successful since the beginning. The involvement and active participation of individual and organizational actors in both ventures - as promoters and as participants - have been possible in the light of the co-existence of three intangible resources having both an individual and a collective/relational nature: passion, trust and knowledge.

Passion, in both cases, acts as the "triggering factor" for the launch of the ventures (Guercini and Cova, 2018) and takes the form of a combination of EP (Cardon et al., 2009) and DP (Milanesi, 2018). In the RATATÀ case, founders have a strong passion for artistic forms in the graphics/illustration context (DP) and are willing to realize a great project in this creative field (EP). Their passion and commitment are increasingly shared by various individual and organizational actors who contribute in terms of time, energy and creativity. In the ARIA case, founders have a strong desire to create something of their own (EP) and exploit their professional interests toward an innovative culture of building and furniture (DP). The involvement of collaborators and local organizations in both cases is also because of the contagion effect of their EP (Cardon, 2008) and in the case of RATATÀ to the shared DP. The consolidation of the networks of actors over time is also possible thanks to the "stabilizing" effect of the shared EP and DP, providing cohesion over time. The overcoming of complex difficulties has been possible also thanks to the strong entrepreneurial drive - fueled by EP (Cardon et al., 2009) and by a strong sense of attachment of the leading teams toward the location - their home town - of the event. The development of both ventures has been always linked to the possibility to held the respective events in their original location. The close attachment toward the home-town could be conceived as "passion for place", which could be defined as "strong positive feelings towards a specific location and its community on the basis of personal and/or professional reasons." This type of passion seems to converge with specific DPs highlighted in the literature, such as "passion for social mission" proposed by Cardon et al. (2017).

In both cases, the founders involve local partners and institutional/business actors putting in place their reputation and therefore activating existing relationships based primarily on trust, thus exploiting available resources embedded in the local community of the SMST (Spilling, 2011). The combination of passion and trust/reputation-based relationships makes the project attractive for communities and stakeholders, showing a "contagion effect" (Cardon, 2008).

The "emotional" side of the evolution of the two ventures represented by passion and trust - has been complemented by knowledge and expertise in organizing the events. Organizers in both projects have been able to create something novel in the local and regional context, to the extent that both RATATÀ and ARIA have now become well-known brands - becoming resources themselves - closely linked to their towns and communities. The combination of intangible resources passion, trust/reputation and knowledge/expertise - available at the individual and collective level have been effectively matched with local tangible resources that have been offered and used in terms of towns' buildings, seminar rooms and historical sites. This increasing integration has been recognized by the respective municipalities which in the latter phases perceive both projects as strategic for making their towns more cohesive internally and more open externally.

In synthesis (Figure 1), the empirical evidence discussed in this paper highlights that individual and collective passion - 
both EP and DP - could represent a hidden resource able to ignite and sustain innovative entrepreneurial projects attempting to combine locally embedded resources - trustbased social networks, professional expertise and artistic creativity - in SMSTs and communities where renewal and development is often difficult to promote. Notably, EP enables the entrepreneurial team to move forward in the venture involving first the close community and then exploiting key business and institutional relationships, while DP - in its specific declinations including also passion for place - exerts considerable impulse to connect people and organizations sharing common interest and values around the project.

\section{Conclusions}

This paper aims at contributing to the ongoing debate on the importance of entrepreneurship development in the context of SMSTs, which has been neglected in recent studies, more oriented to examine the role played by big cities or larger urban areas (Bell and Jayne, 2009). Notably, we intend to gain a deeper understanding of the features of PDEVs emergence within SMSTs and related communities, to provide insights over the relevance of such initiatives in local development (Lysgård, 2016). We attempt to achieve this goal through the empirical analysis of two case studies from Italy: RATATÀ - an entrepreneurial project in the cultural sector in the town of Macerata - and ARIA - an event-based start-up in the building/ furnishing sector in the town of Fano. The empirical analysis and the discussion is conducted through the conceptual lenses of the IMP approach and of the ARA framework, which is deemed useful - through its emphasis on actors, activities and resources in interaction processes - to understand the main features of PDEVs in SMSTs.

These two empirical cases show that passion - in this paper conceptualized as EP and DP - could emerge as one of the key resources in transforming the initial idea into a real entrepreneurial venture in resource-scarce peripheral settings, as in the case of some SMSTs. This is evident in two main patterns highlighted in the empirical analysis and related to the leading teams of the PDEVs. First, passion is a resource able to activate the involvement of actors and thus facilitate access to the limited existing resources within the SMST context. This is shown by the contagion effect of EP (Cardon, 2008) and by the depth of sharing of DP in local communities and related networks (Milanesi, 2018). In both cases, the pre-existing social and business ties - based on trust - have been relevant for the start-up and development of the entrepreneurial project (Aaboen et al., 2017). Second, PDEVs have been able to overcome complex challenges - often unexpected - also thanks to the combination of EP and DP. EP is a powerful resource fueling the entrepreneurial effort when both internal and contextual difficulties emerge, while DP influences the entrepreneurial behavior through its values and social underpinnings providing stability and direction to the leading team.

Figure 1 The emergence of a PDEV

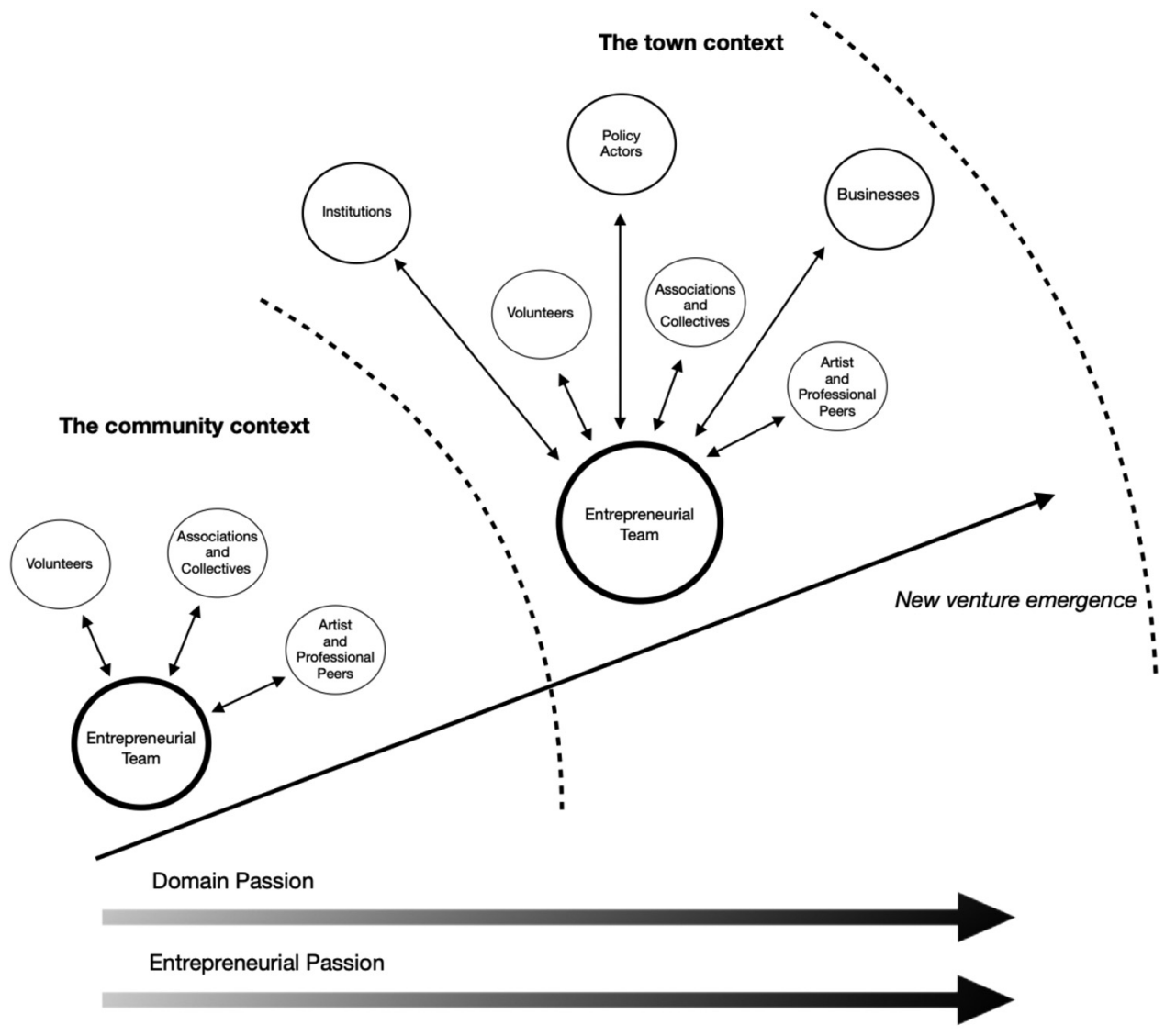


From a more conceptual perspective, this paper proposes to investigate in more depth, the connection between passion and SMSTs, in line with a recent call for research on "emotions" in entrepreneurship (Shepherd, 2015). Notably, we argue that specific dimensions of DP could be emphasized, as the empirical analysis has shown. "Passion for place" could represent a distinct and complementary typology of passion fostering entrepreneurial effort in a specific locally contextualized setting. As the two cases have shown, the founders have chosen to devote all their effort and the collected resources for a project to be developed in their home town. This insight is in line with recent contributions examining passiondriven entrepreneurship and the location of professional and business activities (Guercini and Ceccarelli, 2020).

The paper has also limitations. Both RATATÀ and ARIA cases concern event-based entrepreneurship, which has de facto a collective orientation. Moreover, the two cases have been developed through the perspective of the entrepreneurial ventures, while a more comprehensive perspective of other involved actors is lacking. Further research could explore more in-depth, the perspective of the local institutions and their evolving role in support of passion-driven entrepreneurship.

This research on PDEVs in SMSTs provides interesting managerial and policy implications. Under a managerial perspective, passion - in terms of EP and DP - could represent a key resource for potential entrepreneurs fueling the start-up process in such complex settings as SMSTs. EP could be actively searched in team formation to foster the initial entrepreneurial drive and then it could be exploited to promote contagion (Cardon, 2008) and marketing visibility of the new venture in the local setting and the specific market. DP instead could represent a complementary resource as it fosters stability in interaction processes and reinforces shared identities, as in the case of common "passion for place" stimulating joint effort. Passion as a resource should be, however, combined with appropriate managerial skills, as the empirical cases show.

Under a policy perspective, this research on PDEVs in SMSTs highlights that supporting the emergence of these types of initiatives could provide various benefits to the local economic and social context. For SMSTs suffering an economic downturn, passion could represent a hidden resource able to ignite a variety of entrepreneurial processes with both non-profit and profit orientation (Crick et al., 2020). This could generate value for the community in the case of postdisaster contexts requiring a creative effort in both business and social settings (Cameron et al., 2018). Therefore, the first task for policymakers should be directed toward active monitoring of what is under the surface of local economic and cultural activism, which then could be turned in viable new business ventures. Support toward nascent PDEVs could be implemented through a variety of mechanisms. First, policymakers might set up training programs to strengthen managerial skills of potential "passion-driven" entrepreneurs. Second, local policies could provide ad hoc financial support for well-designed projects attempting to exploit this pool of shared passions and interests. Third, they might play an active role in helping local PDEVs in networking activities with other organizations, firms and universities, active both inside and outside the boundaries of the SMSTs. These policies could provide support to the development of PDEVs and increase their chance to grow and survive, thus becoming a source of resources and opportunities for the local community and the whole SMST.

\section{References}

Aaboen, L., La Rocca, A., Lind, F., Perna, A. and Shih, T. (Eds) (2017), "Starting up in business networks", Why Relationships Matter in Entrepreneurship, Palgrave, London.

Baraldi, E., Havenvid, M.I., Linné, Å. and Öberg, C. (2018), "Start-ups and networks: interactive perspectives and a research agenda", Industrial Marketing Management, Vol. 80, pp. 58-67.

Bell, D. and Jayne, M. (2009), "Small cities? Towards a research agenda", International fournal of Urban and Regional Research, Vol. 33 No. 3, pp. 683-699.

Cameron, T., Moore, K., Montgomery, R. and Stewart, E.J. (2018), "Creative ventures and the personalities that activate them in a post-disaster setting", Creativity and Innovation Management, Vol. 27 No. 3, pp. 335-347.

Cannatelli, B., Pedrini, M. and Braun, M. (2019), "Individuallevel antecedents of the entrepreneurial approach: the role of different types of passion in the Italian craft brewing industry", International Entrepreneurship and Management Fournal, Vol. 15 No. 4, pp. 1193-1219.

Cardon, M.S. (2008), "Is passion contagious? The transference of entrepreneurial passion to employees", Human Resource Management Review, Vol. 18 No. 2, pp. 77-86.

Cardon, M.S., Glauser, M. and Murnieks, C.Y. (2017), "Passion for what? Expanding the domains of entrepreneurial passion", fournal of Business Venturing Insights, Vol. 8, pp. 24-32.

Cardon, M.S., Wincent, J., Singh, J. and Drnovsek, M. (2009), "The nature and experience of entrepreneurial passion", Academy of Management Review, Vol. 34 No. 3, pp. 511-532.

CEC (2011), Cities of Tomorrow. Challenges, Visions, Ways Forward, Commission of the European Communities, Brussels.

Ciabuschi, F., Perna, A. and Snehota, I. (2012), "Assembling resources when forming a new business", fournal of Business Research, Vol. 65 No. 2, pp. 220-229.

Crick, J.M., Crick, D. and Chaudhry, S. (2020), "Entrepreneurial marketing decision-making in rapidly internationalising and de-internationalising start-up firms", Fournal of Business Research, Vol. 113 No. 1, pp. 158-167.

Dubois, A. and Gadde, L.-E. (2002), "Systematic combining: an abductive approach to case research", fournal of Business Research, Vol. 55 No. 7, pp. 553-560.

Easton, G. (2010), "Critical realism in case study research", Industrial Marketing Management, Vol. 39 No. 1, pp. 118-128.

Guercini, S. and Ceccarelli, D. (2020), "Passion driving entrepreneurship and lifestyle migration: insights from the Lutherie of Cremona", fournal of International Entrepreneurship, doi: 10.1007/s10843-020-00269-1.

Guercini, S. and Cova, B. (2018), "Unconventional entrepreneurship", fournal of Business Research, Vol. 92, pp. 385-391. 
Håkansson, H. and Snehota, I. (1995), Developing Relationships in Business Networks, Routledge, London.

Håkansson, H., Ford, D., Gadde, L.-E., Snehota, I. and Waluszewski, A. (2009), Business in Networks, Wiley.

Halinen, A. and Törnroos, J.-Å. (2005), "Using case methods in the study of contemporary business networks", fournal of Business Research, Vol. 58 No. 9, pp. 1285-1297.

Havenvid, I.M. and La Rocca, A. (2017), "New business development in business networks", in Håkansson, H., and Snehota, I. (Eds) No Business is an Island: Making Sense of the Interactive Business World, Emerald.

Hite, J.M. (2003), "Patterns of multidimensionality among embedded network ties: a typology of relational embeddedness in emerging entrepreneurial firms", Strategic Organization, Vol. 1 No. 1, pp. 9-49.

Johannisson, B. and Nilsson, A. (1989), "Community entrepreneurs: networking for local development", Entrepreneurship \& Regional Development, Vol. 1 No. 1, pp. 3-19.

La Rocca, A., Hoholm, T. and Mørk, B.E. (2017), "Practice theory and the study of interaction in business relationships: some methodological implications", Industrial Marketing Management, Vol. 60, pp. 187-195.

Lysgård, H.K. (2016), “The 'actually existing' cultural policy and culture-led strategies of rural places and small towns", Fournal of Rural Studies, Vol. 44, pp. 1-11.

McGrath, H., O'Toole, T. and Canning, L. (2019), "Coopetition: a fundamental feature of entrepreneurial firms' collaborative dynamics”, Fournal of Business $\mathcal{E}$ Industrial Marketing, Vol. 34 No. 7, pp. 1555-1569.

McKeever, E., Jack, S. and Anderson, A. (2015), "Embedded entrepreneurship in the creative re-construction of place", Fournal of Business Venturing, Vol. 30 No. 1, pp. 50-65.

Mayer, H. and Motoyama, Y. (2017), "Entrepreneurship in small and medium-sized towns/communities", Entrepreneurship $\mathcal{E}$ Regional Development, Vol. 29 No. 9/10, pp. 1015-1016.

Milanesi, M. (2018), "Exploring passion in hobby-related entrepreneurship. Evidence from Italian cases", fournal of Business Research, Vol. 92, pp. 423-430.

Newman, A., Deakin, A., Obschonka, M., Moeller, J. and Chandan, G.G. (2019), "Entrepreneurial passion: a review, synthesis, and agenda for future research", Applied Psychology, doi: 10.1111/apps.12236.

Patton, M.Q. (1990), Qualitative Research \& Evaluation Methods, SAGE Publications.
Quintens, L. and Matthyssens, P. (2010), "Involving the process dimensions of time in case-based research", Industrial Marketing Management, Vol. 39 No. 1, pp. 91-99.

Servillo, L., Atkinson, R. and Hamdouch, A. (2017), "Small and medium-sized towns in Europe: conceptual, methodological and policy issues", Tijdschrift Voor Economische en Sociale Geografie, Vol. 108 No. 4, pp. 365-379.

Sharafizad, J. and Brown, K. (2020), "Regional small businesses' personal and inter-firm networks", fournal of Business \& Industrial Marketing, doi: 10.1108/JBIM-092019-0432.

Shepherd, D. (2015), "Party on! a call for entrepreneurship research that is more interactive, activity based, cognitively hot, compassionate and prosocial”, fournal of Business Venturing, Vol. 30 No. 4, pp. 489-507.

Snehota, I. (2011), "New business formation in business networks", IMP fournal, Vol. 5 No. 1, pp. 1-9.

Spilling, O.R. (2011), "Mobilising the entrepreneurial potential in local community development", Entrepreneurship E Regional Development, Vol. 23 Nos 1/2, pp. 23-35.

Trettin, L. and Welter, F. (2011), "Challenges for spatially oriented entrepreneurship research", Entrepreneurship \& Regional Development, Vol. 23 Nos 7/8, pp. 575-602.

Welter, F. (2011), "Contextualizing entrepreneurship conceptual challenges and ways forward", Entrepreneurship Theory and Practice, Vol. 35 No. 1, pp. 165-184.

Welter, F., and Gartner, W.B. (Eds) (2016), A Research Agenda for Entrepreneurship and Context, Edward Elgar, Northampton.

Welter, F., Baker, T. and Wirsching, K. (2019), "Three waves and counting: the rising tide of contextualization in entrepreneurship research", Small Business Economics, Vol. 52 No. 2, pp. 319-330.

Welter, F., Baker, T., Audretsch, D.B. and Gartner, W.B. (2017), "Everyday entrepreneurship - a call for entrepreneurship research to embrace entrepreneurial diversity", Entrepreneurship Theory and Practice, Vol. 41 No. 3, pp. 311-321.

Yin, R.K. (2003), Case Study Research: Design and Methods, (3rd ed.), Sage, Thousand Oaks.

\section{Corresponding author}

Roberta Bocconcelli can be contacted at: roberta. bocconcelli@uniurb.it 